\title{
Development of IgG responses to mycobacterial antigens
}

\author{
Clarissa Pilkington, A M de L Costello, G A W Rook, J L Stanford
}

\begin{abstract}
Recent studies link mycobacterial and human heat shock protein antigens with autoimmune diseases. Little is known about the development of antibody responses to these antigens in children. IgG responses to mycobacterial antigens were studied in children living in the UK (an environment low in mycobacteria) who had not received BCG vaccination.

Age curves of IgG response to sonicates from different species of mycobacteria were similar suggesting that the greater part of the developing IgG response is to the common antigens shared by all mycobacteria. The major part of the IgG response was to carbohydrate antigens: lipoarabinomannan is a mycobacterial cell wall carbohydrate and was confirmed as a major immunodominant antigen. Infants showed a marked early response to the mycobacterial 65 kilodalton (kDa) and $70 \mathrm{kDa}$ heat shock proteins, but not to the human $65 \mathrm{kDa}$ heat shock protein. The early IgG response to heat shock proteins may reflect cross reactivity to proteins released by a wide variety of bacteria (possibly from breakdown in the gut) or recognition of other immunodominant antigens with high levels of cross reactivity to self.

(Arch Dis Child 1993; 69: 644-649)
\end{abstract}

An understanding of the development of antibody responses to mycobacterial antigens in children has potentially important applications. Firstly, antigens useful for serodiagnosis of tuberculosis might be sought by comparing antibody responses in children living in environments with many or few mycobacteria, in children before and after they receive BCG vaccination, and during the active tuberculous infection. Secondly, antibody may play a functional part in preventing or limiting dissemination of mycobacterial infection. ${ }^{1}$ Tuberculosis control programmes in developing countries have not been successful ${ }^{2}$ and with the rising incidence of mycobacterial disease in association with HIV infection there is a need for alternative approaches to vaccination.

Finally, several of the major immunogenic antigens of mycobacteria (as well as a wide variety of bacterial, protozoal, and helminth infections) have been identified as members of heat shock protein families. Some authors have suggested a fundamental role for these immunologically dominant antigens that mimic self in the evolution and development of the immune system. ${ }^{3}$ There is also evidence that abnormal responses to major mycobacterial antigens with sequence homology to human proteins, for example the 65 kilodalton $(\mathrm{kDa})$ heat shock protein, may be associated with the pathogenesis of diseases like rheumatoid arthritis, ${ }^{4-7}$ atherosclerosis, ${ }^{8}$ and diabetes mellitus. ${ }^{9}$ An understanding of immune responses to these antigens in children could throw light on the development of autoimmune processes and why the incidence of these diseases varies in different environments.

We have studied the development of antibody responses to sonicates of a variety of species of mycobacteria and to purified mycobacterial antigens, including the 65 and $70 \mathrm{kDa}$ heat shock proteins and the cell wall antigen lipoarabinomannan, in unvaccinated children living in the UK.

\section{Subjects and methods}

SERUM COLLECTIONS

Aliquots of serum from children being bled for other reasons were obtained from University College and Middlesex hospitals. Ethical permission was obtained from the hospital ethical committee for the analysis of stored sera. Sera were stored at $-20^{\circ} \mathrm{C}$ and divided into aliquots to avoid multiple freeze-thaw cycles. We studied antibody responses to sonicated antigen preparations from cultures of different species of mycobacteria in the first 131 children bled. Studies of purified and recombinant antigens were conducted on a separate sample of 173 unvaccinated children which included 99 samples from the first serum collection in which residual serum was available. Details of age, current illness (if any), and a history of BCG vaccination or presence of BCG scar were recorded. Children with a certain or unknown history of BCG vaccination were excluded from the analysis.

\section{ENZYME LINKED IMMUNOSORBENT ASSAY} (ELISA) TESTS

Assays were devised to measure IgG responses to a selection of mycobacterial antigens.

\section{Antigens}

(A) Sonicates - Filtered sonicate preparations of eight mycobacterial species were prepared: slow growers Mycobacterium avium, $M$ scrofulaceum, $M$ kansasii, and $M$ tuberculosis and fast growers $M$ vaccae, $M$ flavescens, $M$ fortuitum, $M$ non-chromogenicum. Organisms were grown on Sauton's medium solidified 
with $1.5 \%$ agar and were harvested with a spatula. The organisms were suspended in $0.067 \mathrm{M}$ borate buffered saline $(\mathrm{pH} 8.0)$ and sonicated. The sonicate was filtered $(0.2 \mu \mathrm{m}$ pore size) and the protein concentration was determined spectrophotometrically by the method of Warburg and Christian. ${ }^{10}$ The sonicate was diluted to $1 \mathrm{mg} / \mathrm{ml}$ in borate buffer and stored at $4^{\circ} \mathrm{C}$.

(B) Purified mycobacterial antigens - Three species of the $65 \mathrm{kDa}$ heat shock protein were studied: mycobacterial (from BCG), Escherichia coli, and recombinant human. The $65 \mathrm{kDa}$ antigen of BCG was provided by Dr Jan van Embden (Bilthoven, the Netherlands), recombinant human $65 \mathrm{kDa}$ from Professor R S Gupta (Toronto), and $E$ coli $65 \mathrm{kDa}$ and the mycobacterial $70 \mathrm{kDa}$ protein was provided by Dr D Young (Hammersmith, London).

Lipoarabinomannan (from $M$ tuberculosis) was provided by $\mathrm{Dr}$ Carlos Moreno from the Medical Research Council Unit for Tuberculosis and Related Infections, Hammersmith.

The solid phase ELISA was conducted according to the principles outlined by Nassau et al. ${ }^{11}$ Antigen solutions were diluted in $0.05 \mathrm{M}$ sodium carbonate coating buffer ( $\mathrm{pH} 9 \cdot 6$ ). After coating the plates were washed and blocked with $2 \%$ bovine serum albumin (BSA) in phosphate buffered saline (PBS) with $0.05 \%$ Tween $20(\mathrm{pH} \mathrm{7 \cdot 2)}$ for one hour and the plates stored at $-20^{\circ} \mathrm{C}$.

\section{Sera and conjugates}

These were also diluted in PBS-Tween 2\% BSA solution and the plates were washed with this solution three times after each stage of the test.

\section{Optimal conditions for the test sera}

These were found from chequerboard titrations to be: (A) for sonicates: $2 \mu \mathrm{g} / \mathrm{ml}$ of antigen for coating the ELISA microtitre trays (Nunc Maxisorb) at room temperature for three hours; $1 / 1000$ dilution of the test sera; $1 / 3000$ dilution of rabbit antihuman IgG conjugated to peroxidase (Dako) at $32^{\circ} \mathrm{C}$ for three hours. (B) For 65 and $70 \mathrm{kDa}$ protein: $2 \mu \mathrm{g} / \mathrm{ml}$ overnight at $4^{\circ} \mathrm{C}, 1 / 200$ dilution of test sera, $1 / 1000$ dilution of antihuman IgG at $32^{\circ} \mathrm{C}$ for three hours. Such serum dilutions were found to be within the linear phase of an antibody binding curve. (C) for lipoarabinomannan: 2 $\mu \mathrm{g} / \mathrm{ml}$ of antigen for coating the ELISA microtitre trays at room temperature for three hours; $1 / 200$ dilution of the test sera; $1 / 3000$ dilution of rabbit antihuman IgG conjugated to peroxidase (Dako) at $32^{\circ} \mathrm{C}$ for three hours.

\section{Substrate}

The substrate used was 2,2'-azino-di(3-ethylbenzthiazoline sulphonic acid) and hydrogen peroxide in citrate phosphate buffer ( $\mathrm{pH} \mathrm{4} \cdot 1)$. The reaction was stopped after 30 minutes' incubation in the dark by addition of sodium fluoride.

\section{ELISA results}

These were expressed as the mean optical density of duplicates (absorbance measured at $490 \mathrm{~nm}$ on a Titertek multiscan ELISA reader) calculated as a percentage of the mean optical density of an adult positive control serum tested on the same plate. The optical density values from control wells coated with buffer but no antigen were deducted from the mean optical density of each test and positive control serum to control for non-specific background binding. To correct for variation in the optical densities of the positive controls for different antigens we applied a correction factor (the mean of the positive control optical densities for each antigen divided by a fixed mid-range optical density, that is $0 \cdot 5$.). For analysis of the results BCG vaccinated children were excluded and the children were divided into eight age groups: the geometric mean of the optical densities for each age group was used (because the responses were not normally distributed) to construct the relevant age curves.

\section{Specificity of the ELISA tests}

This was checked by preincubating positive control serum with a variety of mycobacterial and control antigens: suspensions of Pseudomonas spp, E coli, group B streptococcus, and Staphylococcus aureus. The blocking effect of antigens was assessed from log serum dilution curves of optical density.

\section{MEASUREMENT OF IgG SUBCLASS RESPONSES}

ELISA tests for subclass estimation were similar to those described above with the following alterations: $50 \mu \mathrm{l}$ quantities were used for all reagents; sera at 1/500 dilution; anti-IgG subclass 1 and 2 monoclonals (from Cambridge Bioscience) used at 1/1000 dilution, anti-IgG ${ }_{3}$ at $1 / 500$ dilution all incubated at $4^{\circ} \mathrm{C}$ overnight; streptavidin conjugated to peroxidase at dilution of $1 / 8000$ for three hours at $32^{\circ} \mathrm{C}$; substrate and stopping solution as above; results of antibody absorbance measured as above but expressed as mean optical density after subtraction of the optical density obtained from wells coated with antigen but without test serum (to eliminate the effects of non-specific binding of the monoclonals); for each subclass and plate the same positive control serum was used (from a child with tuberculosis) and interplate variations in optical density were corrected using the positive control optical density.

ASSESSMENT OF CARBOHYDRATE $v$ PROTEIN ANTIGEN IgG RESPONSES

Columns of wells from plates coated with antigen were treated with either trypsin $(15 \mu \mathrm{g} / \mathrm{ml}$ at $32^{\circ} \mathrm{C}$ for six hours), sodium metaperiodate solution $\left(0.075 \mathrm{M}\right.$ at $4^{\circ} \mathrm{C}$ overnight), or trypsin and periodate sequentially. Trypsin digests protein antigens and periodate solution oxidises carbohydrate residues by cleaving the alkyl chain of sialic acid and other vicinyl hydroxyls to form aldehyde groups. After 

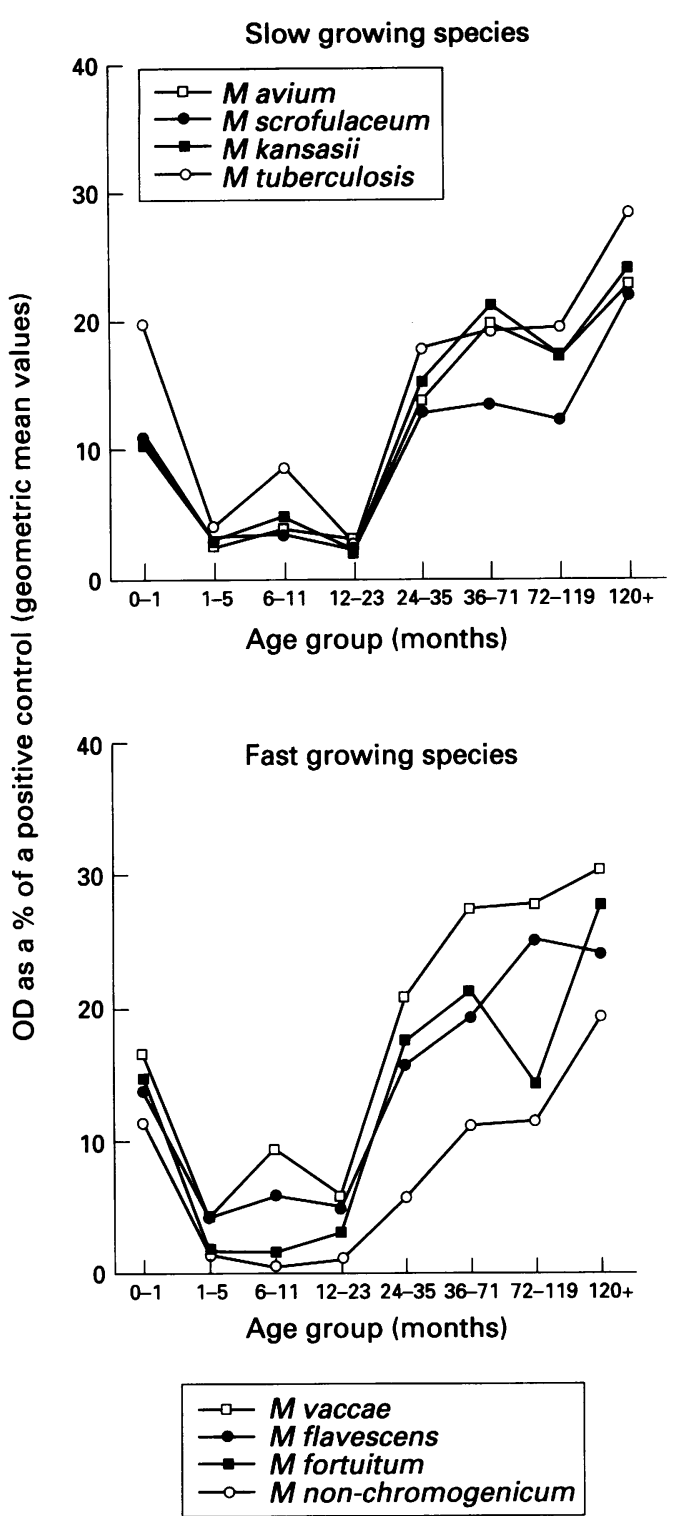

Figure 1 Development of IgG responses to sonicates of slow and fast growing mycobacteria in UK children who had not received BCG vaccination. Results shown as the geometric mean value (for each age group) of the optical density (OD) expressed as a percentage of an adult positive control.

periodate treatment, wells were incubated with $2 \%$ ethanolamine made up in carbonate buffer $\mathrm{pH} 9.6$ for three hours at $32^{\circ} \mathrm{C}$. The ethanolamine reduces the reactive aldehyde groups. Pretreated plates were then tested for IgG responses using the ELISA test described.

\section{TOTAL IMMUNOGLOBULINS}

Total immunoglobulins were measured using radial immunodiffusion.

\section{Results}

SPECIFICITY OF THE ELISA TESTS

Mycobacterial whole cell sonicate ELISA tests were effectively blocked by preincubation with sonicated antigen, and partly blocked by whole live mycobacteria and lipoarabinomannan (because the sonicate mixture contains lipoarabinomannan). Control antigens had no effect. The lipoarabinomannan ELISA test was effectively blocked by preincubation with lipoarabinomannan and partly blocked by sonicated mycobacterial antigen but not by control antigens. The $65 \mathrm{kDa}$ protein test was blocked by $65 \mathrm{kDa}$ protein and by live $E$ coli but no other control antigens. The $E$ coli $\mathrm{kDa}$ protein is known to share extensive sequence homology with its mycobacterial counterpart. $^{12}$

\section{IgG RESPONSES TO SONICATES}

Age curves to fast and slow grower whole cell sonicates were as shown in fig 1 . High IgG concentrations in cord blood and the first month of life to all sonicate antigens fell to a trough during the first year. The response patterns for all species of both fast and slow growing mycobacteria were almost identical, which suggests that the greater part of the developing IgG response is to the common (or group i) antigens shared by all mycobacterial. ${ }^{13}$

Trypsin and periodate blocking experiments demonstrated that the majority of the total IgG response to sonicate antigens was to their carbohydrate rather than protein components. When the mean value of the IgG response to $M$ vaccae sonicate was expressed as $100 \%(n=83$ sera), trypsin digestion reduced the IgG response to $66 \%$ of mean value, periodate to $15 \%$, and the response was totally abolished if wells were pretreated with both periodate and trypsin.

IgG RESPONSES TO HEAT SHOCK PROTEINS: MYCOBACTERIAL, E COLI AND HUMAN $65 \mathrm{kDa}$, AND MYCOBACTERIAL $70 \mathrm{kDa}$

The response to purified and recombinant heat shock protein antigens in UK children is quite different than from sonicate antigens (fig 2). Infants show a significant early response to the bacterial $65 \mathrm{kDa}$ heat shock proteins. This occurs around 6 months of age after maternal IgG has disappeared. The response appeared to peak at 6-24 months of age and then decline (although the sample size in each age group was relatively small). The early response to 65 $\mathrm{kDa}$ heat shock proteins was unexpected, however, as children make relatively little antibody at this age. Expressing the heat shock protein response as a proportion of total IgG (measured from radial immunodiffusion) further accentuated the early peak.

The IgG responses to the mycobacterial and $E$ coli $65 \mathrm{kDa}$ proteins were highly correlated $(\mathrm{p}<0.001$, Spearman rank correlation coefficient $\left.\left(r_{s}\right)=0.496\right)$. This may be due to cross reactivity for shared immunodominant epitopes or alternatively because children are similarly exposed to the two antigens at the same age. By contrast there appears to be no significant response to the recombinant human $65 \mathrm{kDa}$ heat shock protein at any age studied. A weak positive response was noted in only six individuals, all of different ages.

IgG RESPONSES TO LIPOARABINOMANNAN

There was very little response to lipoarabinomannan before the age of 24 months (fig 3). 


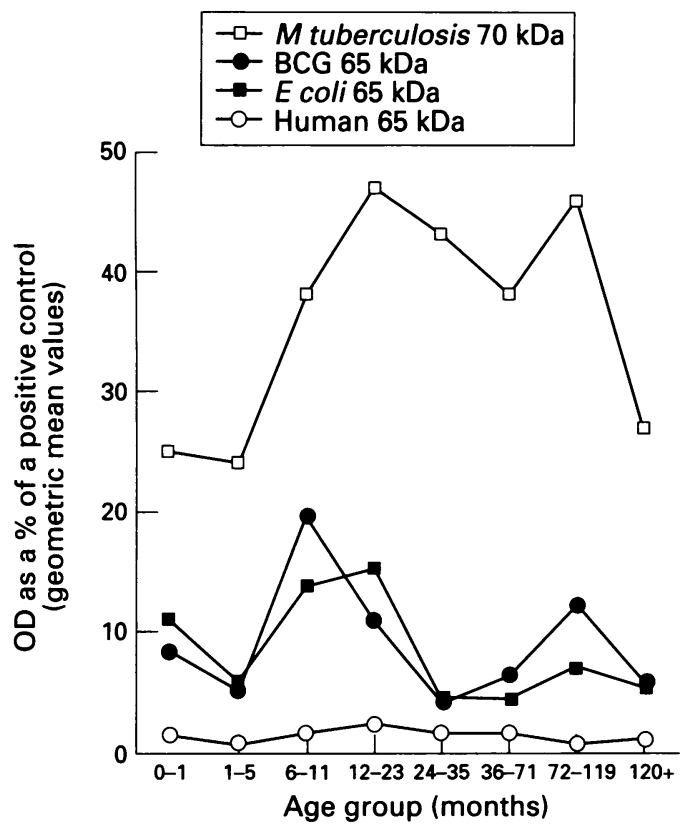

Figure 2 Development of IgG responses to mycobacterial, $\mathrm{E}$ coli, and human heat shock proteins in UK children who had not received BCG vaccination. Results shown as the geometric mean value (for each age group) of the optical density $(O D)$ expressed as a percentage of an adult positive control.

IgG responses to polysaccharides were predominantly in the $\mathrm{IgG}_{2}$ subclass which is not produced in significant quantity before 2 years of age.

IgG SUBCLASS RESPONSES IN UK CHILDREN These showed that almost all the response to sonicated mycobacteria was in the $\operatorname{IgG}_{2}$ subclass; $\mathrm{IgG}_{1}$ and $\mathrm{IgG}_{3}$ responses were virtually undetectable in all age groups (fig 4 ).

\section{Discussion}

IgG RESPONSES TO MYCOBACTERIAL SONICATES AND LIPOARABINOMANNAN

Our results have shown a natural age curve of IgG response to mycobacteria even in noninfected children from the UK living in an environment low in mycobacteria. The pattern and degree of response to a wide variety of mycobacterial species (both fast and slow growers) is similar. This suggests that most of the IgG response is to the common (group i) mycobacterial antigens rather than species or subgroup specific antigens (group ii-iv). ${ }^{13}$ Antigens that elicit a protective response against mycobacteria are thought to be largely from the shared antigens as BCG is at least as good a vaccine against leprosy as it is against tuberculosis ${ }^{1415}$ so this antibody response (or any $\mathrm{T}$ cell response which accompanies it) in healthy unvaccinated children may confer some protection against infection.

The high concentration of antimycobacterial IgG circulating in the first few weeks of life could possibly exert other effects, for example interference with the immunogenicity of BCG. Tuberculin conversion rates are significantly lower in children vaccinated in the newborn period compared with those vaccinated at

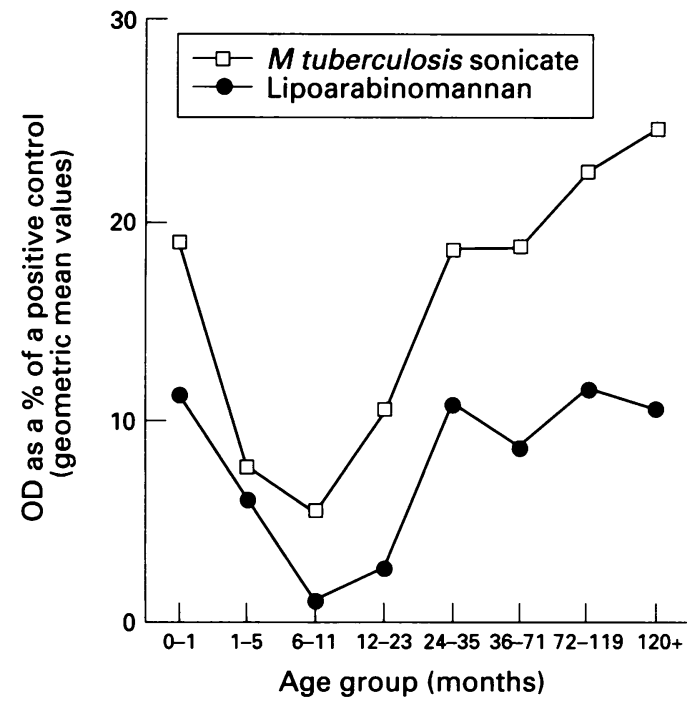

Figure 3 IgG response to purified lipoarabinomannan from $M$ tuberculosis in UK children who had not received $B C G$ vaccination. Results shown as the geometric mean value (for each age group) of the optical density (OD) expressed as a percentage of an adult positive control.

more than 6 weeks of age ${ }^{16}$ and the protective efficacy of the vaccine may show a similar pattern. It would be interesting to study differences in the quantity and persistence of maternally transmitted antibody in different environments as this could be an additional factor in explaining the significant geographical variation in the impact of BCG vaccine. The World Health Organisation currently recommends that countries with a high incidence of tuberculosis should give the $B C G$ vaccination neonatally.

Periodate oxidation of antigens in ELISA wells almost abolished the IgG response to sonicates and confirmed that the major part of this IgG response is probably to carbohydrate antigens. It might be that trypsin digestion also releases carbohydrate bound to protein to a very limited extent but the major immunodominant carbohydrate antigen, lipoarabinomannan, is not protein bound and crosses the mycobacterial cell membrane. Purified lipoarabino-

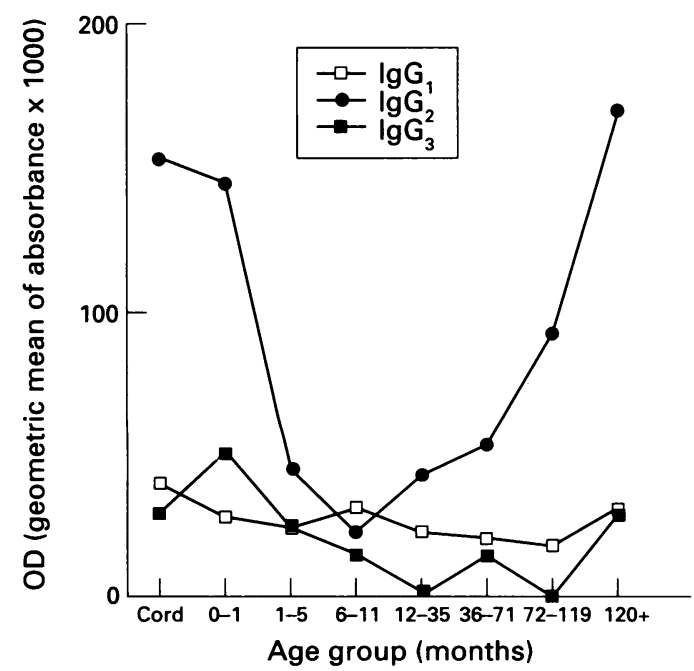

Figure 4 IgG subclass responses to sonicated $\mathrm{M}$ tuberculosis in UK children who had not received $B C G$ vaccination. Results shown as the geometric mean value (for each age group) of optical density (OD). 
mannan is known to bind to ELISA plates through its lipid moiety. Experiments in the mouse have shown the opposite effect - that trypsin rather than periodate abolishes the IgG response to mycobacterial antigens suggesting that mouse antibodies are directed mainly at protein epitopes compared with the infants' predominant antibody response to carbohydrate. This immunodominance pattern in children may partly explain why the antibody response is so variable after contact with mycobacteria: complex carbohydrates tend to be $\mathrm{T}$ independent antigens and probably elicit only a weak primary IgG response. Young children are unable to respond to polysaccharide antigens: capsulated bacteria like haemophilus and pneumococcus induce weak protective antibody responses and non-conjugate polysaccharide vaccines are unsuccessful under 2 years of age.

$\mathrm{IgG}_{2}$ subclass antibody isotype accounted for almost all the IgG response to sonicates in all age groups in UK children. $\operatorname{IgG}_{2}$ characteristically binds to carbohydrate antigens but it was surprising that the potentially more useful complement fixing $\operatorname{IgG}_{1}$ and $\mathrm{IgG}_{3}$ isotypes did not appear with age in our serum collections. In view of the strong response to purified heat shock protein antigens in young children and the absent response to sonicates in the same age group, it seems likely that immunodominant heat shock protein epitopes were not exposed by the sonication process, or that these epitopes constituted a minor fraction of the components of the sonicate which bound to the wells. By contrast lipoarabinomannan appeared to be a major immunodominant component of the sonicated mycobacterial antigen: the age response in children to purified lipoarabinomannan was almost identical to the sonicate curves and the response of the positive control serum to sonicates was largely blocked by preincubation with lipoarabinomannan suggesting that much of the response was to the bacterial surface.

\section{HEAT SHOCK PROTEIN RESPONSES}

This is the first description of the antibody response pattern to mycobacterial heat shock proteins in childhood. The significant early response in UK children was surprising and the function of these antibodies is not yet clear. Is the response simply caused by early exposure to a wide variety of bacteria all of which produce immunodominant and cross reactive heat shock proteins? Previous studies have shown that a proportion of healthy adults not known to be previously exposed to mycobacteria have antibody and $T$ cell responses to the mycobacterial $65 \mathrm{kDa}$ protein ${ }^{7}$ and in mice a high proportion of neonatal thymocytes respond to the $65 \mathrm{kDa}$ antigen. ${ }^{17}$ Recognition of mycobacterial $65 \mathrm{kDa}$ by $\gamma \delta \mathrm{T}$ cells in mice led to the suggestion that the enhanced immunogenicity of heat shock proteins may reflect a fundamental role for these antigens in the evolution of the immune system, that is a primitive $\gamma \delta$ system of surveillance develops into more specific $\alpha \beta T$ cell responses. ${ }^{18}$
However, this has not yet been shown with human $\gamma \delta \mathrm{T}$ cells.

It may be that responses to heat shock proteins are one example of a wider phenomenon whereby a large proportion of the antibody response in infancy is to self antigens ${ }^{19}$ or to antigens that are conserved in all life forms and therefore enable rapid recognition of any infectious agent. ${ }^{3}$ These authors imply that with increasing age the response should become more discriminatory, and responses to those epitopes that cross react with self should be lost. Such hypotheses therefore predict a significant but diminishing response to the human heat shock protein in young children, but we found no response to this protein. It would be interesting to compare the epitope pattern of the $65 \mathrm{kDa}$ protein species that children do respond to. Jones et al describe the sequence homology between heat shock proteins and a wide range of autoantigens ${ }^{20}$ so our finding of a lack of antibody response to the human $65 \mathrm{kDa}$ heat shock protein does not rule out cross reactivity with these other antigens. Also the antibody response to some cross reactive antigens may be suppressed by normal immune mechanisms in children. This should be a stimulus to further studies.

The children also showed a significant response to the mycobacterial $70 \mathrm{kDa}$ protein. The $70 \mathrm{kDa}$ heat shock protein are immunodominant in the antibody response to schistosomiasis, leishmaniasis, and lymphatic and ocular filariasis. Two heat shock protein 70 genes are localised within the major histocompatibility complex region of human chromosome $6 .^{21}$ The $70 \mathrm{kDa}$ heat shock protein molecules function in normal cells by binding to unfolded proteins and facilitating their transport across lipid bilayers. They are believed to play a part in antigen processing and presentation. ${ }^{22}$ It is not clear whether the response we observed to the mycobacterial $70 \mathrm{kDa}$ reflects cross reactivity to $70 \mathrm{kDa}$ proteins released by a wide variety of bacteria (possibly from breakdown in the gut) or a specific response to environmental mycobacteria.

Our study raises many questions. It will be interesting to compare antibody responses in an environment where the antigen load is much higher or in a population with high BCG coverage. Exposure to environmental mycobacteria in water is lower in the $\mathrm{UK}^{23}$ than in other countries (such as India and parts of the USA) as indeed are rates of tuberculin positivity in unvaccinated children. ${ }^{14}$ It will also be valuable to study the development of antibody in those infected children who mount a strong antibody response and to see if and when isotypic switching occurs.

We are grateful to the Middlesex Hospital Special Trustees and to the British Paediatric Association for providing fellowships to conduct this research.

1 Costello AM de L, Kumar A, Narayan V, et al. Does antibody to mycobacterial antigens, including lipoarabinoTrans $R$ Soc Trop Med Hyg 1992; 86: 686-92.

2 Styblo K. Overview and epidemiological assessment of the current global tuberculosis situation: with an emphasis on current global tuberculosis situation: with an emphasis on 1989; 11 (suppl 2): S339-446. 
3 Cohen IR, Young DB. Autoimmunity, microbial immunity and the immunological homunculus. Immunol Today 1991; 12: 105-10.

4 Lydyard PM, Tsoulfa G, Sharif M, et al. Immunity to heat shock proteins in rheumatoid arthritis. Clin Exp Rheumatol 1990; 8: 69-74.

5 Bahr GM, Rook GAW, Al-Saffar M, Embden JV, Stanford $\mathrm{J}$, Behbehani K. Antibody levels to mycobacteria in relation to HLA type: evidence for non-HLA linked high levels of antibody to the $65 \mathrm{kDa}$ heat shock protein of $\mathrm{M}$ tuberculosis in rheumatoid arthritis. Clin Exp Immunol 1988; 74: 211-5.

6 Res PCM, Schaar CG, Breedveld FC, et al. Synovial fluid T cell reactivity against $65 \mathrm{kD}$ heat shock protein of mycobacteria in early chronic arthritis. Lancet 1988; ii: 478-80.

7 Lamb JR, Bal V, Mendez Samperio P, et al. Stress proteins may provide a link between the immune response to infection and autoimmunity. International Immunolog 1989; 1: 191-6.

$8 \mathrm{Xu} \mathrm{Q}$ Willeit J, Marosi M, et al. Association of serum antibodies to heat shock protein 65 with carotid atherosclerosis. Lancet 1993; 341: 255-9.

9 Elias D, Markovits D, Reshef T, van der Zee R, Cohen IR. Induction of autoimmune diabetes in the non-obese diabetic (NOD/Lt) mouse by a $65 \mathrm{kDa}$ heat shock protein. betic (NOD/Lt) mouse by a $65 \mathrm{kDa}$ heat shoc
Proc Natl Acad Sci USA 1990; 87: 1576-80.

10 Thorne CJR. Techniques in protein and enzyme biochemistry. Part 1. Vol Section B104. Holland: Elsevier, 1978.

11 Nassau E, Parsons ER, Johnson GD. The detection of antibodies to $M$ tuberculosis by microplate ELISA. Tubercle 1976; 57: 67-70.

12 Young DB, Mehlert A. Serology of mycobacteria: characterisation of antigens recognised by monoclonal antibodies. Rev Infect Dis 1989; 11 (suppl 2): S431-5.

13 Stanford JL, Grange JM. The meaning and structure of species as applied to mycobacteria. Tubercle 1974; 55: 143-52.

14 Stanford JL, Shield MJ, Rook GAW. How environmental mycobacteria may predetermine the protective efficacy of BCG. Tubercle 1981; 62: 55-62.

15 Pönnighaus J, Fine P, Sterne J, et al. Efficacy of BCG against leprosy and tuberculosis in northern Malawi. against leprosy and tuber

16 Illdirim I, Sapan N, Cavusoglu B. Comparison of BCG vaccination at birth and at third month of life. Arch Dis Child 1992; 67: 80-2.

17 O'Brien RL, Happ P, Dallas A, Palmer E, Kubo R, Born WK. Stimulation of a major subset of lymphocytes expressing $\mathrm{T}$ cell receptor gamma delta by an antigen derived from Mycobacterium tuberculosis. Cell 1989; 57: 667-74.

18 Young RA, Elliott TJ. Stress proteins, infection and immune surveillance. Cell 1989; 59: 5-8.

19 Avrameas S. Natural autoantibodies: from 'horror autotoxicus' to 'gnothi seauton'. Immunol Today 1991; 12: $154-8$.

20 Jones DB, Coulson AFW, Duff GW. Sequence homologies between hsp60 and autoantigens. Immunol Today 1993; 14: $115-8$

21 Sargent CA, Dunham I, Trowsdale J, Campbell RD. Human major histocompatibility complex contains genes for the major heat shock protein hsp70. Proc Natl Acad Sci USA 1989; 86: 1968-72.

22 Elliott T. Stress proteins. In: Roitt IM, Delves PJ, eds. Encyclopedia of immunology. London: Academic Press, 1992: 1402-5.

23 Collins $\mathrm{CH}$, Grange JM, Yates MD. Mycobacteria in water. f Appl Bacteriol 1984; 57: 193-211. 